\title{
Key elements of the tutorial support management model
}

\author{
Grace Lynch and Philip Paasuke \\ Open Universities Australia
}

\author{
An Outstanding Paper Award recipient, ascilite Sydney 2010 Conference
}

\begin{abstract}
In response to an exponential growth in enrolments the Tutorial Support Management (TSM) model has been adopted by Open Universities Australia (OUA) after a two-year project on the provision of online tutor support in first year, online undergraduate units. The essential focus of the TSM model was the development of a systemic approach to the provision of online tutorial support for high enrolment units. Findings from this project indicate that the TSM model has provided benefits in terms of improved student retention, performance, and satisfaction in addition to increased return and reenrolment rates. This paper outlines the key elements of the TSM model and offers comments on various issues that need to be taken into account in adopting this model.
\end{abstract}

\section{Background}

Open Universities Australia (OUA) is a company owned by seven leading universities in Australia and is the country's fastest growing provider of online higher education services with over 110,000 people having studied through OUA since it began operations in 1993. With over 900 units and 60 qualifications from 15 Australian prestigious universities and TAFE colleges, it offers a wide range of tertiary level education programs enabling students to graduate with a degree from an Australian university. For the purposes of this paper these seven shareholder and eight partner universities in OUA are collectively referred to as Providers.

In response to the exponential growth in enrolments over the past four years, a special initiative known as the Tutorial Support Management (TSM) project was developed and trialed. The primary purpose of this project was to investigate a model of tutor training, supervision, and task/time assignment that supported the use of multiple online tutors to assist in facilitating high enrolment online units while maintaining quality teaching and learning outcomes on a cost-effective basis. All Providers were invited to participate in the project with a focus on the highest enrolment first year undergraduate units. During 2008 and 2009 the Royal Melbourne Institute of Technology (RMIT) in Victoria, Griffith University in Queensland, University of South Australia (UniSA) in South Australia and Curtin University in Western Australia implemented the TSM model in 35 units across 7 study periods with over 22,000 students supported by 140 online tutors. The disciplines covered included accounting, computer studies, criminology, business, internet studies, arts and primary education.

As part of the formal evaluation of the TSM project, analyses and reports were prepared throughout the trial and evidence gathered to date has shown that the TSM 
model has the potential to provide significant benefits in terms of contributing to the development of a model of online education for units with large enrolments (in excess of 350 students) that improves the overall quality of educational outcomes for students in a cost effective manner. When the TSM model is implemented as designed there are improvements in student retention, pass rates, grades distribution and satisfaction. In addition, students return to take more units than previously via OUA. On the basis of reports prepared during this two year period, the OUA Board has adopted the TSM model as standard practice for large undergraduate units and subsequently a series of academic papers have been prepared to document the experience and further consider the implications of the project. This paper outlines the key elements of the TSM model as it has been adapted over the two year duration and concludes with comments on various issues that need to be taken into account in implementing the TSM model. Additional papers have also been written on this project providing more in depth evidence of the improvement in student outcomes and satisfaction as well as an analysis of tutor time and activity (see also Lynch \& Paasuke, 2010a, 2010b).

\section{Asynchronous discussion forums, educational research and the TSM model}

As indicated in the background section, the essential focus of the TSM model concerns the development of a systematic approach to the provision of online tutorial support for high enrolment units. The principal focus for the provision of this support is through the use of asynchronous discussion forums (ADFs), which have become 'increasingly integrated into online learning environments' (Topçu, 2008, p.901). ADFs are 'asynchronous' because the participants involved are not required to participate simultaneously (as is the case with 'synchronous' tools). ADFs are not the only tool with this asynchronous capability but, for a number of reasons, they have become one of the most commonly used methods for enabling this form of online interaction (Penny \& Murphy, 2009, p.804). Specific applications of ADFs within teaching and learning include encouraging students to ask questions about various issues, guiding students through particular learning activities, and enabling students to discuss various issues with one another (Thorpe, 2008, pp.59, 62-64). ADFs have been identified as having a number of important strengths including the following:

- They are robust and relatively easy to use. As part of a virtual learning environment (VLE) framework within a university context, ADFs are supported by IT Help staff.

- They provide a cost effective and time efficient means for tutors to engage in dialogue with their students in comparison with other means such as email (Bender, 2004, pp.116-117).

- The asynchronous dimension of ADFs offers learners a greater degree of flexibility than synchronous modes of learning. This means that people who would otherwise be unable to participate in learning are able to do so (Wang, S., 2008, p.2).

- The asynchronous nature of ADFs also enables participants to have greater time for reflection before posting their responses. This capacity for reflection has been linked to higher order cognitive processing which 'helps the learner integrate and recognize global patterns and relationships, which lead to knowledge creation ... and intellectual development' (LaPointe, 2008, p.4). Moreover, as learners share their reflections in this environment, all participants can benefit (Weller, 2002, p.82). 
Such observations lead Garrison and Anderson (2003, p.26) to argue that ADFs can be used 'to support collaborative, constructivist approaches to learning'.

- The focus on text-based forms of representation leads to benefits for learners in terms of improving both their thinking and writing skills. As Ong quoted in Burkdall (2009) writes: 'To make yourself clear without gesture, without facial expression, without intonation, without a real hearer, you have to foresee circumspectly all possible meanings a statement may have for any possible reader in any possible situation, and you have to make your language work so as to come clear all by itself'. Thompson (2009) cites a recent study by Lunsford which has found evidence to suggest that because it involves regular practice in writing for an audience, the use of ADFs is contributing to a 'literacy revolution'.

- ADFs can also act as a supportive mechanism for learners and reduce feelings of isolation (Dixon, Dixon \& Axmann, 2008, p.259; Palmer, Hold \& Bray, 2008, p.848).

In addition to these acknowledged benefits, encouraging students to participate in the use of ADFs as part of their online studies is also consistent with the latest research concerning the link between student success and the importance of participation in groups for student learning. As John Seely Brown (2007) has noted:

One of the few deeply robust results in most educational theory today is, in fact, the best indicator of success in college has to do with whether or not you know how to form, join, participate in study groups bar none. That result has been replicated time and time again in one form or another. And that sense of the study group is actually where real learning happens in terms of how do you take what you've been given as information or knowledge? How do you internalise it in your own particular frame? And the curious thing is that these notions of study groups ... work in a distributed way just as well as face to face.

By using tutors to facilitate student-centred learning in online discussion groups, the TSM model also corresponds to the perceived need to shift the focus from a 'Cartesian view of learning', of 'pedagogy as knowledge transfer', towards one based on 'the social view of learning' and 'understanding as socially constructed' (Brown \& Adler, 2008, pp. 18-19). As these authors explain further:

This perspective also helps to explain the effectiveness of study groups. Students in these groups can ask questions to clarify areas of uncertainty or confusion, can improve their grasp of the material by hearing the answers to questions from fellow students, and perhaps most powerfully, can take on the role of teacher to help other group members benefit from their understanding (one of the best ways to learn something is, after all, to teach it to others). (Brown \& Adler, 2008, p. 18).

While ADFs have the potential to promote such benefits as those described above, there is no guarantee that this will actually occur. One of the problems which can arise is that students only participate in ADFs to a limited extent. For example, Thorpe (2008, p.60) writes that 'the use of conferencing has not produced easy wins in terms of high levels of participation and quality contribution by students'. Similarly, one recent research study by Conole, de Laat, Dillon \& Darby (2008, pp.516-17) found that students 'appear to be ambivalent about the use of discussion forums', and prefer to communicate directly with students using other 'communication channels' such as 'text, chat, etc'. The reasons cited include the following: 'it was possible that one or two individuals could dominate the discussions ... the time lag between message posting 
and responses [can be] frustrating ... it was not always possible to engage with issues at a deep level'.

One of the critical factors in ensuring the successful use of ADFs is the role played by online tutors in motivating and engaging students. There is now an extensive body of literature concerning the importance of effective facilitation skills (Collison, 2000; Salmon, 2000; Bender, 2003; Betts, 2009). However, as McPherson and Nunes (2009, p.235) point out, online learning initiatives often tend to privilege a focus on 'design' while 'insufficient attention is given to the delivery process'. As these authors state further:

These efforts have little chance of succeeding without a tutoring team that has the appropriate online tutoring skills necessary to explore and maximize the designed environments ... the tutoring team is at least as important as the design team

(McPherson \& Nunes, 2009, p.235)

As will be discussed in the following section of this paper, adopting an effective approach to ensuring that tutors both develop and then apply effective tutoring skills as part of their role has been identified as being one of the key elements necessary to ensure the successful implementation of the TSM model.

\section{Key elements of the TSM model}

As initially conceived, the TSM model comprised a number of key elements including:

1. Lowering the student:tutor ratio in high enrolment units.

2. Determining the required number of tutors, the means for identifying and contracting the tutors.

3. Organising and delivering paid tutor training in online student-centred discussion (OSCD).

4. Preparation of Tutor guides by course coordinators to be provided to tutors.

5. Tutor facilitation of weekly, structured, asynchronous, content-related, online student centred discussions, as well as other means of support such as email.

6. Tutors to maintain a log of activities.

7. The employment of a TSM Project Manager and Online Tutor Supervisor to offer coordination and support to Providers implementing the TSM model and to review the results of these activities.

The following discussion elaborates on each of these elements in greater detail.

\section{Lowering the student:tutor ratio in high enrolment units}

As noted in the background section of this paper, one of the issues which has confronted OUA in recent years has been how to manage the exponential growth in enrolments within particular units. As part of the response to this issue, it was felt that there was a need to increase online tutoring support in undergraduate units with high enrolments. Prior to the Tutorial Support Management (TSM) model being adopted, it had been common practice within a number of units that only one staff member, in most cases the course coordinator, be allocated the task of managing an online unit, including all discussion forums and email communication with students, irrespective of the number of students involved. That meant that in some units with over 400 to 900 students only one staff member was responsible for responding and managing the students as one online group. 
By seeking to reduce this student:tutor ratio, the TSM model aimed to provide a mechanism for ensuring a consistent approach across different units and Providers in relation to high enrolment units but maintained Provider's ownership of unit content, materials and quality. This approach had multiple objectives. One of the key purposes was to ensure that students received the necessary support from online tutors as part of their educational experience. It was hoped that this in turn would bring about improvements in retention, pass rates, re-enrolments and student satisfaction. In addition, the model also aimed to increase levels of tutor satisfaction by focusing on more efficient and effective means of facilitation of learning groups and correspondingly reducing the demand for one on one support from unit tutors. It was also hoped that the model would reduce workload burdens on course coordinators by relieving them of the task of having to tutor online, and shifting the focus to responsibilities relating to overall coordination of the unit and leadership of their new teams of tutors.

At the outset of the first phase of the TSM project, it was initially felt that the goal should be to ensure that the student:tutor ratio be no greater than 100:1 and that there were possible benefits from dividing up the students into smaller online discussion groups of 30 students per tutor. However, by the end of the first year these figures were revised to the point where it was recommended that a Tutor could effectively manage groups which start with an initial enrolment of no more than 200 students. The reasons for this are discussed in more detail in a separate paper on the TSM project which specifically addresses student and tutor activity. However, essentially these reasons relate to the evidence that over the duration of a study period, the extent of student activity in smaller groups declines to the point where a critical mass for generating discussion often no longer exists.

This is a significant finding particularly as it challenges the widely held view as expressed in various literature relating to online tutoring that advocate much smaller group sizes. For example, Bender (2003, p.119) recommends that the optimal size of a group (depending on class size) should not exceed four or five people'. Similarly, Wang, X. (2008, p.205) recommends 'small groups of 4-6 as learning communities for discussion so the peers will have sufficient input from each other yet still find it easy to keep track of all the postings in each new thread'. By contrast, the idea that online discussion groups of 200 can operate on a viable basis is more in keeping with the idea of the 'Dunbar number' of 150 (Godin, 2009) for a sustainable social network, or the higher number of 291 as postulated by (McCarty et al., 2001, p.28). Both of these theories of course have a tolerance range, which makes a number of 200 seem a reasonable midpoint to settle on, particularly when online discussion groups will inevitably experience some attrition and are also unlikely to engage all participants, however engaging the course activities and online tutor may be.

One important caveat to this discussion is that if a unit is to somehow incorporate online discussion as a significant part of the assessment, then this is likely to impact on the capacity of tutors to cope with a group of this size. However, for the most part, the units involved in the TSM project have not assessed online discussions thereby making a group of this size quite manageable. This number of 200 has in turn led to the definition of a high enrolment undergraduate unit which is suitable for the adoption of a TSM model as being in excess of 350-400 students, that is, a unit employing at least two tutors. 


\section{Determining the required number of tutors and the means of identifying and contracting them}

Once it had been resolved that particular units would adopt the TSM model, there was a need to work with course coordinators and other relevant stakeholders on a number of issues in order to establish the basis for implementation. These issues included determining the number of tutors which would be required and also the means for identifying and contracting the tutors. At the commencement of the TSM, it was thought initially that OUA may play a role in sourcing tutors. However, in practice it turned out to be the preferred option of Providers to source their own tutors, based on their knowledge of individuals who had previously undertaken tutoring or who were deemed suitable to take on this role.

The tutors employed as part of the TSM project have been from a diverse background. One of the common profiles has been of emerging academics in their late-20s to early30 s, who have already undertaken face to face tutoring and are often in the process of commencing $\mathrm{PhD}$ studies. Such individuals have viewed the opportunity to participate in the TSM trial as an opportunity to gain some practical experience of online tutoring. As well other common profiles have included:

- current academics who due to the changing nature of their family, require flexible working hours combined with a desire to work from home and found online tutoring a perfect solution;

- individuals employed full time in professions such as accounting who saw online tutoring as a means of sharing their expertise more widely;

- full time academics in mid-career looking to supplement income by taking on additional roles as online tutors; and

- semi-retired academics who viewed online tutoring as an opportunity to remain active in a field in which they have extensive knowledge and experience.

During the first phase of the TSM project, when OUA directly employed the tutors, a guaranteed base fee payment was determined as the best option, since part of the trial was to gain a deeper understanding of workload for online tutors and an appropriate student/tutor ratio. This fee was derived from previous experiences which estimated that the allocation of 100 students per tutor would require an average of 10 hours per week over a 13 week study period. A comparative analysis of sessional tutor rates found that a base salary of $\$ 4,000$ AUD was consistent with current practice. For tutors who also undertook marking as part of the TSM trial an additional 100 hours were included, which meant a base salary of $\$ 7,000$ AUD.

In the second year of the trial, the Providers directly employed the tutors while OUA maintained employment of an Online Tutor Supervisor and Project Manager to support the course coordinators and online tutors. Based on evidence from the first year of the trial there was the expectation that tutors would work on average of between 5 and 7 hours per week facilitating online discussion, chats and email communication with a student:tutor ratio of 200:1. As tutors eventually may be employed by more than one Provider, payment conditions and workload equity issues were considered and formed the rationale for a recommended remuneration of between $\$ 3,250$ and $\$ 3,500$ AUD per study period (hourly rate of approximately $\$ 55$ AUD). This payment would be for supporting students online, with Providers basing decisions for marking payments on their existing formulas. However, in practice, Providers directly employed tutors in 2009 under different sessional loads and rates 
and the student:tutor ratio varied from a low of 75 to a high of 400 , while payments varied from a low of about $\$ 1,660$ AUD to a high of $\$ 5,000$ AUD per study period.

\section{Organising and delivering paid tutor training}

Another significant element of the TSM model was the requirement that tutors be paid to undertake a short training and professional development course in Online Student Centred Discussion (OSCD). This course has previously been discussed as part of a paper by Dixon et al. (2008). As these authors note, the course has its origins in 'Wright and Shoop's (2003) Student-Centred Discussion Model which places ongoing discussion at the centre of the learning process' (Dixon et al., 2008, p.256). This model was subsequently adapted by Axmann 'for the online environment in order to engage student discussion and interactive skills' (Dixon et al., 2008, p.256). In this format, the OSCD model is 'designed to develop online protocols and communication tools to enhance critical thinking skills, provide for peer assessment, group activities and progress lifelong learning skills in a cooperative collaborative manner' (Dixon et al., 2008, p.256). In this format, participants engage in a four week online course designed to develop these skills and is currently delivered through the RMIT learning management system via Blackboard. During 2008 and 2009, 91 participants successfully completed the course (many of the tutors in 2009 had also participated in 2008). An additional means of support offered during 2009 was the use of face to face workshops to introduce some of the principles with a view to encouraging participants to undertake the full online course.

One of the essential ideas underpinning the idea of encouraging prospective tutors to undertake an online course is that participants can derive significant benefits from learning about online facilitation through undertaking a course within the online environment itself. Such an experience means that the learning which takes place is not just about acquiring an understanding of the relevant intellectual principles, it is also a relevant experiential dimension to their learning. This point is similarly made in relation to another tutor training course by Børsheim, Schaathun, Skauerud, Spjelkavik \& Willbergh (2009, p.294) who state that one of their aims was that 'the course should be a model course that could induce the prospective tutors to reflect upon the experience of being a student'. For example, in adopting the role of 'student' in such an online course, participants are able to get a better understanding of what it feels like to be an online student and are therefore more able to understand and empathise with the feelings of their own students when they return to take on their actual courses. Many participants undertaking the course have made statements along the lines of 'now I know how my students feel'. This can relate to such issues as ambiguity of course instructions when other group members are not participating to the same extent, or simply the difficulties associated with combining online study with other commitments such as work, family and formal postgraduate studies (Dixon et al., 2008).

Engaging in this course has assisted prospective tutors in preparing for their role as online tutors in ways which can assist them in maximising student engagement, and hence creating opportunities for learning. The majority of tutors and course coordinators found this a critical element of success in the TSM trial. For example, a survey of tutors who participated in the TSM during 2008 found that $91 \%$ of tutors undertaking the OSCD training believed that it had been helpful in assisting them to take on the role of TSM tutors. Dixon et al. (2008) also report evidence of positive feedback from course participants and moreover, as evidenced by the sample 
comments included below the tutors who participated in subsequent OSCD training sessions during 2009 have also found it to be enormously beneficial:

I was actually surprised to find it useful as I am a bit cynical about staff training courses!! However, as we sat 'rejigging' a unit yesterday I found myself using ideas from the discussions and readings, so THANK YOU!!...

Thank you for your facilitation of the course. It was a great online environment that fostered communication ...

I tried implementing many of the suggestions from earlier weeks and the icebreaker worked very well. I tried also to set more definite parameters as to availability and so far this seems to be working well.

\section{Preparation of tutor guides}

A further important concept of the TSM model has been the idea of developing content-specific tutor guides for particular units. The purpose of preparing tutor guides is to ensure quality assurance for the course coordinator as well as to improve student retention by creating a well-organised and thorough guide for tutors which is specific to individual units. Such a guide should provide advice to tutors on key points or concepts to be emphasised with students on a weekly or topic basis. The idea is that such guides should be written by course coordinators and that copies be provided to tutors involved in their respective units prior to the start of a study period.

In order to assist course coordinators with the task of writing such guides, a template document has been developed for authors which incorporates basic guidance and provides a sense of the structure to be adopted. Course coordinators have also been provided with sample tutor guides as exemplars of the approach to be adopted. In addition, within the template document, part of the advice given to course coordinators authoring such guides is as follows:

Imagine you are writing it for a tutor who is coming into the unit for the first time and you want them to fulfill the role of tutoring online. As such it should outline your expectations of the tutor and provide them with specific guidance as to how to perform their role in relation to the unit.

Due to the differences in approach taken in particular units, it is emphasised that there is 'no one size fits all' approach. However, it is suggested that most tutor guides can incorporate the following basic structural elements such as an introduction outlining the unit context and purposes, an overview of preparation time, online discussion and suggestions about responding to emails (e.g. amount of time, e.g. 5-7 hours per week, 24 hour turnaround on responses to students, etc, and detailed week by week summaries of tutor tasks for the unit, including annotated commentary material, learning activities, highlight flashpoints and suggested responses).

During 2008, coordinators and tutors involved in the TSM project were surveyed about their attitudes towards the idea of creating and using tutors guides and it was found that $86 \%$ of course coordinators agreed that preparing the tutor guides had been an important element of the trial while 95\% of tutors indicated that the tutorial guides were helpful in preparing for their role as part of the TSM project. 


\section{Tutor facilitation}

This part of the model involved tutors providing online support to students through the use of ADFs. Following the model articulated as part of the OSCD online training course, during week 1 , tutors were to lead the students through some initial 'icebreaker' activities in order to ensure that students were comfortable with communicating in the online environment, getting to know each other and start interacting with their tutor. During subsequent weeks the support provided by tutors was to be focused on encouraging and guiding the students to undertake a series of structured activities which were aligned with the unit topics and learning outcomes. These activities had been previously developed by course coordinators as part of the tutor guides with which they were provided at the commencement of the unit. This approach was designed to ensure a high degree of consistency amongst multiple tutors across each unit. In addition to working through these structured activities, tutors were to respond to student queries about other aspects of the unit, including issues relating to assignments and exams. An important aspect of the TSM model, which was also promoted to tutors, both through the OSCD training and the tutor guides, was the importance of a responding to student postings within 24 hours with allowances for a longer delay on weekends.

A concluding point is that future directions for online tutor facilitation as part of a TSM model may also incorporate the use of tools such as Elluminate Live! (Elluminate, 2001-2009), which incorporates a number of synchronous modes of communication including Voice over Internet Protocol (VoIP), video, text chat, as well as hand raising, polling and emoticon tools (Rowe \& Ellis, 2008a, 2008b). Elluminate also includes a whiteboard space which can be used to display prepared presentations, add images, write live text, conduct web tours and share applications (Elluminate, 2001-2009). One of the units which was part of the TSM in SP3 2009 trialed the use of Elluminate. The adoption of this tool was undertaken as an alternative to the synchronous text-chat tool within Blackboard. To date only a minority of students have taken up the offer of participating in these sessions. However, the sessions were also recorded and made available to students who are unable to attend the live sessions. The early anecdotal feedback provided by students indicates that they appreciate the option of communicating with tutors via this alternative channel in addition to the use of ADFs. This form of support offers interesting possibilities for future forms of tutor-led support sessions for students as an addition to the use of asynchronous discussion forums. At a minimum this evidence supports the view of Chundur and Prakash (2009, p.5) that 'more objective research is required to determine the ways in which synchronous and asynchronous online discussion can be combined to maximize student learning'.

\section{Tutors' log of activities}

During the first phase of the TSM model an essential element of the trial was for tutors to maintain a weekly log of activities via a web based timesheet adapted from Replicon (2009). Tutors had individual logins and were encouraged to record their times against specific activities. The specific set of categories were as follows: initial set up of discussion forums, creating and setting announcements, conducting warm-up activities with students, weekly discussion queries, email communication, assessment advice, other administrative matters and marking. One of the goals of the TSM project was to gain a better sense of the time tutors actually spend on providing online support and the time they spend on performing other specific tasks. It was an analysis 
of this data which led to the finding that whereas during the first phase of the TSM project tutors had been allocated approximately 10 hours per week, they actually spent an average of 5-7 hours per week and that tutors were capable of managing larger numbers of students than first thought. A further discovery was that tutors actually spent time before and after the actual 13 week study period in getting prepared and finalising marking and for many tutors, previously, this work had been unpaid (Lynch \& Paasuke, 2010b).

\section{Role of TSM Project Manager and Online Tutor Supervisor}

The final element of the TSM model has been the role played by the OUA Project Manager and Online Tutor Supervisor in providing tutors and coordinators with a central point of contact for resolving any particular problems as well as extending best practice across Providers, especially as they were located in four different states across Australia. This mechanism provided an effective means for promoting coordination, consistency and ongoing support with the implementation of TSM, including a coordination of unavoidable tutor absences during study periods, which minimised disruption to students. A supplementary coordination mechanism employed during the first phase of the project was a TSM Advisory Committee, which included key representatives from all Providers involved in the project.

During the project, face to face meetings with Provider staff as well as teleconferences and email communication were utilised so that course coordinators and tutors could provide feedback on their experiences in relation to the actual delivery of TSM units. Ongoing support provided by the Online Tutor Supervisor included editorial feedback on tutor guides being developed by course coordinators, the provision of advice on possible approaches to configuring the set up of ADFs for particular units and giving assistance to tutors to update the web timesheet system. In addition, the Online Tutor Supervisor monitored the ADFs for particular TSM units to collect data on student and tutor activity and, if necessary, provided feedback to course coordinators and tutors on any significant issues.

As the number of units adopting the TSM model has continued to expand and responsibilities for the contracting of tutors have been devolved to Providers, the extent of central coordination has decreased. One of the reasons for this trend has been the practicalities associated with maintaining central coordination as the scale of the project has widened. Looking to the future, it is possible that if more units continue to adopt the TSM model, then the provision of support to stakeholders using such mechanisms may require a more extensive team with additional staff being located geographically closer to Providers in order to ensure that support is available when required.

\section{Conclusion}

The essential brief of the OUA TSM project has been to formulate, trial and evaluate a coordinated and systematic approach to training and employing additional tutors in individual units that have increasing numbers of enrolments. However, as shown by the evidence assembled over the two years, the TSM model has the potential to provide significant benefits in terms of contributing to developing a model of online education that improves the overall quality of educational outcomes for students in a cost-effective model. Other OUA papers prepared provide detailed evidence that the adoption of the TSM model can contribute to improvements in student satisfaction, 
student retention, pass rates and grades distribution and in addition, to increased student return for further units and at a higher unit yield per student. For example, of the 20 units with comparative data, 12 units improved retention from a low improvement of $3 \%$ to a high improvement of $24 \%$, for an average improvement in student retention of $8.75 \%$. Similarly, in relation to pass rates in $75 \%$ of TSM units analysed, the percentage of students receiving a passing grade increased by an average 12.6 percentage points from a low of $3.9 \%$ to a high of $28.7 \%$ change in over 5,300 students. In addition to increasing the actual number of students passing the units compared to previously, the grades distribution also improved with greater percentages of students receiving distinctions and high distinctions in $60 \%$ of units analysed to date and greater percentages of students receiving credits rather than passes in 13 of the 15 units (Lynch \& Paasuke, 2010a).

In conclusion, it is important not to view the TSM model as a panacea for improving learning outcomes for all OUA units. Even if this component of a course is wellorganised, there is a host of other issues which can adversely affect the ability of students to succeed - for example, issues such as incorrect textbook information or supply issues, slow return of assignments and inherent problems with the relationship between curriculum design and assessment. However, as one component of an overall approach to online education, the TSM model offers enormous potential. It must be acknowledged that as this project has shown there can be variations in the way that a TSM model is implemented, which can have a significant impact on outcomes. A key issue concerns the extent of the variation in the salaries and employment conditions of tutors which carries the associated risk that student:tutor ratios will be higher than the recommended figure of 200 per tutor and in addition, the payments to tutors may be lower than the recommended level. Such variations in practice may in turn result in the attraction of a lower quality pool of talented staff than was previously the case, as well as result in reduced service levels being provided to students. As discussed in an accompanying paper on student and tutor activity, the authors argue that in the case of units which have employed a lower number of tutors for a greater number of students, there appears to be evidence of a correlation with reduced student retention, performance and satisfaction.

In order to address such issues, the authors of this paper argue that probably the best strategy to address these issues is to continue conducting analysis of outcomes and disseminating these findings, in order to demonstrate which TSM approaches are most successful in achieving the goal of adopting a model which is both cost-effective as well as capable of generating improved outcomes for all of the stakeholders involved in the learning process.

\section{References}

Bender, T. (2003). Discussion-based online teaching to enhance student learning: Theory, practice and assessment. Sterling, VA: Stylus Publishing.

Betts, K. (2009). Lost in translation: Importance of effective communication in online education. Online Journal of Distance Learning Administration, 12(2). [viewed 31 Aug 2009]. http:/ / www.westga.edu/ distance/ojdla/ summer122/ betts122.html

Børsheim, I., Schaathun, A., Skauerud, H.O., Spjelkavik, U. \& Willbergh, I. (2009). Educating tutors - and ourselves. A report from a collective effort. In U. Bernath, A. Szücs, A. Tait \& M. Vidal (Eds.), Distance and e-learning in transition: Learning innovation, technology and social challenges. (pp.291-299). London and Hoboken, NJ: ISTE/Wiley. 
Brown, J. S. (2007). Keynote session of The Open Learn Conference: Researching open content in education. 30 October 2007 (webcast, viewed 4 Dec 2009).

http: / / stadium.open.ac.uk/ stadia / preview.php?whichevent=1063\&s=31

Brown, J. S. \& Adler, R. P. (2008). Minds on fire: Open education, the long tail, and Learning 2.0. EDUCAUSE Review, 43(1), 16-32. (viewed 4 Dec 2009). http: / / connect.educause.edu/ Library/EDUCAUSE+Review/MindsonFireOpenEducationt/45823

Burkdall, T. (2009). The persistence of writing. EDUCAUSE Review, 44(3), 58-59. http: / / www.educause.edu / EDUCAUSE+Review / EDUCAUSEReviewMagazineVolume44 / ThePersistenceofWriting/171782

Collison, G., Elbaum, B., Haavind, S. \& Tinker, R. (2000). Facilitating online learning: Effective strategies for moderators. Madison, WI: Atwood Publishing.

Conole, G., de Laat, M., Dillon, T. \& Darby, J. (2008). 'Disruptive technologies', 'pedagogical innovation': What's new? Findings from an in-depth study of students' use and perception of technology. Computers \& Education, 50(2), 511-524.

Chundur, S. \& Prakash, S. (2009). Synchronous vs asynchronous communications: What works best in an online environment? Lessons learnt. In Proceedings of World Conference on Educational Multimedia, Hypermedia and Telecommunications, 2009 (pp.3541-3545). Chesapeake, VA: AACE.

Dixon, R. C., Dixon, K. C. \& Axmann, M. (2008). Online student centred discussion: Creating a collaborative learning environment. In Hello! Where are you in the landscape of educational technology? Proceedings ascilite Melbourne 2008. http: / / www.ascilite.org.au/conferences/melbourne08/ procs/dixon.pdf

Elluminate (2001-2009). Elluminate Live! http:/ / www.elluminate.com/products/live/index.jsp [viewed 28 Aug 2009].

McCarty, C., Killworth, P. D., Bernard, H. R., Johnsen, E. C. \& Shelley, G. A. (2001). Comparing two methods for estimating network size. Human Organization, 60(1), 28-39.

Garrison, D. \& Anderson, T. (2003). E-Learning in the 21st century: A framework for research practice. London, RoutledgeFalmer.

Godin, S. (2009). Dunbar's Number isn't just a number, it's the law. http: / / sethgodin.typepad.com/seths_blog/2009/10/the-penalty-for-violating-dunbarslaw.html [viewed 4 Dec 2009, verified 2 Feb 2011].

LaPointe, D. (2008). Learners' perspectives about uses of synchronous and asynchronous conferencing systems within an online graduate course: Interpretations through an activity system. University of New Mexico. [viewed 4 Dec 2009]. http: / / repository.unm.edu/handle/1928/6919

Lynch, G. \& Paasuke, P. (2010a). Impact of a tutorial support management model on student performance and satisfaction. In Proceedings of World Conference on Educational Multimedia, Hypermedia and Telecommunications 2010 (pp. 2040-2048). Chesapeake, VA: AACE.

Lynch, G. \& Paasuke, P. (2010b). Tutor activity as part of the tutorial support management model. In Proceedings of World Conference on Educational Multimedia, Hypermedia and Telecommunications 2010 (pp. 2789-2797). Chesapeake, VA: AACE.

McCarty, C., Killworth, P. D., Bernard, H. R., Johnsen, E. C. \& Shelley, G. A. (2001). Comparing two methods for estimating network size. Human Organization, 60(1), 28-39.

McPherson, M. \& Nunes, M. B. (2009). The role of tutors as a fundamental component of online learning support. In U. Bernath, A. Szücs, A. Tait and M. Vidal (Eds.), Distance and e-learning in transition: Learning innovation, technology and social challenges, (pp.235-246), London, Hoboken, NJ: ISTE/Wiley.

Palmer, S., Hold, D. \& Bray, S. (2008). Does the discussion help? The impact of a formally assessed online discussion on final student results. British Journal of Educational Technology, 39(5), 847-858. 
Penny, L. \& Murphy, E. (2009). Rubrics for designing and evaluating online asynchronous discussions. British Journal of Educational Technology, 40(5), 804-820.

Replicon (1996-2009). Replicon Web TimeSheet. http:/ / www.replicon.com/ [viewed 4 Dec 2009]

Rowe, S. \& Ellis, A. (2008a). Can one size fit all? Using web-based audiographics to support more flexible delivery and learning. In Hello! Where are you in the landscape of educational technology? Proceedings ascilite Melbourne 2008. http:// www.ascilite.org.au/conferences/melbourne08/ procs/ rowe.pdf

Rowe, S. \& Ellis, A. (2008b). Enhancing the convenience and flexibility of student learning options: Using recorded audiographic web conferencing sessions. In Proceedings of World Conference on Educational Multimedia, Hypermedia and Telecommunications 2008, (pp. 30363041). Chesapeake, VA: AACE.

Salmon, G. (2000). E-moderating: The key to teaching and learning online. London, Kogan Page.

Thompson, C. (2009). Clive Thompson on the new literacy. Wired Magazine, Issue 17:09. [viewed 15 Sep 2009]. http: / / www.wired.com/techbiz/people/magazine/17-09/st_thompson

Thorpe, M. (2008). Effective online interaction: Mapping course design to bridge from research to practice. Australasian Journal of Educational Technology, 24(1), 57-72. http: / / www.ascilite.org.au/ajet/ajet24/thorpe.html

Topçu, A. (2009). 'Intentional repetition' and learning style: Increasing efficient and cohesive interaction in asynchronous online discussions. British Journal of Educational Technology, 39(5), 901-919.

Wang, S. (2008). The effect of the implementation of webinar learning from student-trainers' perspective. In G. Richards (Ed.), Proceedings of World Conference on E-Learning in Corporate, Government, Healthcare, and Higher Education 2008 (pp.1359-1364). Chesapeake, VA: AACE.

Wang, X. (2008). What factors promote sustained online discussions and collaborative learning in a web-based course? In S. Negash \& M. E. Whitman (Eds.), Handbook of distance learning for real-time and asynchronous information (pp.192-211), Hershey, PA: Information Science Reference.

Weller, M. (2002). Delivering learning on the net: The why, what and how of online education. London: RoutledgeFalmer.

Wright, D. \& Shoop, L. (2003). Implementing quality discussions through student centred discussion. Unpublished workshop materials, University of Penn State, Pennsylvania.

This article received an Outstanding Paper Award at ascilite Sydney 2010, gaining the additional recognition of republication in AJET (with minor revisions). The reference for the Conference version is:

Lynch, G. \& Paasuke, P. (2010). Key elements of the tutorial support management model. In Curriculum, technology \& transformation for an unknown future. Proceedings ascilite Sydney 2010. http: / / www.ascilite.org.au/conferences/sydney10/Ascilite\% 20conference $\% 20$ proceedings $\% 202010 /$ Lynchg-full.pdf

Authors: Dr Grace Lynch, Academic Products and Services, Open Universities Australia. Email: grace.lynch@open.edu.au Web: http:/ / www.open.edu.au/

Philip Paasuke, Academic Products and Services, Open Universities Australia. Email: philip.paasuke@open.edu.au Web: http: / / www.open.edu.au /

Please cite as: Lynch, G. \& Paasuke, P. (2011). Key elements of the tutorial support management model. Australasian Journal of Educational Technology, 27(1), 28-40. http: / / www.ascilite.org.au/ajet/ajet27/lynch.html 